\title{
Intravenous fluids for pain management in head and neck cancer patients undergoing chemoradiation
}

\author{
Charlotte I. Rivers $^{1,2}$, Austin J. Iovoli ${ }^{1}$, Udit Chatterjee ${ }^{2}$, Gregory M. Hermann ${ }^{1,2}$, Anurag K. Singh ${ }^{1,2}$ \\ ${ }^{1}$ Jacobs School of Medicine and Biomedical Sciences, University at Buffalo, The State University of New York, Buffalo, NY, USA; ${ }^{2}$ Department of \\ Radiation Medicine, Roswell Park Comprehensive Cancer Center, Buffalo, NY, USA \\ Contributions: (I) Conception and design: CI Rivers, AK Singh; (II) Administrative Support: AK Singh; (III) Provision of study materials or patients: \\ AK Singh; (IV) Collection and assembly of data: CI Rivers, AJ Iovoli; (V) Data analysis and interpretation: AJ Iovoli, U Chatterjee, GM Hermann; (VI) \\ Manuscript writing: All authors; (VII) Final approval of manuscript: All authors. \\ Correspondence to: Anurag K. Singh, MD. Roswell Park Comprehensive Cancer Center, 665 Elm St., Buffalo, NY 14203, USA. \\ Email: Anurag.singh@roswellpark.org.
}

Background: Pain due to oral mucositis affects the majority of patients receiving chemoradiation (CRT) for head and neck cancer (HNC), and often results in dehydration. Anecdotally, intravenous (IV) fluids administered during treatment for the resultant dehydration was found to alleviate this pain. The purpose of this retrospective study was to evaluate the effectiveness of IV fluids as a method pain management in this patient population.

Methods: Patients with oral mucositis pain, secondary to CRT for HNC, were given IV fluids according to standard clinic protocol. Patients were evaluated using orthostatic vital signs and prospectively surveyed preand post-IV fluid administration, which included the Visual Analog Scale (VAS) for pain. Difference in pain pre- and post-IV fluid administration was evaluated using a two-tailed paired Student's $t$-test.

Results: Twenty-four patients with a total of 31 fluid administrations was available for analysis. Twentythree patients were receiving or had recently completed CRT. One patient was receiving radiation alone. Six instances of fluid administration were excluded due to: refusal to complete the survey, concurrent pulmonary embolism, concurrent pain medication, and drug seeking behavior. Average pain score decreased from 6.5 [standard deviation (SD) 2.1] prior to IV fluids to 4.0 (SD 2.4) following fluid administration $(\mathrm{P}<0.001)$.

Conclusions: To our knowledge, this is the first report directly correlating IV fluid administration with pain relief, even in the absence of orthostasis. Our findings indicate that in patients undergoing CRT for HNC, the use of IV fluids alone was effective in acutely and significantly reducing pain secondary to oral mucositis.

Keywords: Oral mucositis (OM); radiotherapy; chemotherapy; patient-reported outcomes

Submitted May 14, 2020. Accepted for publication Sep 11, 2020.

doi: $10.21037 /$ atm-20-3910

View this article at: http://dx.doi.org/10.21037/atm-20-3910

\section{Introduction}

Pain due to oral mucositis (OM) affects approximately $80 \%$ of patients who receive chemoradiation (CRT) for head and neck cancer (HNC), and can significantly impact quality of life (1). Pain scores generally increase during treatment, with a noticeable increase near the mid-point of radiation therapy that correlates with worsening mucositis, possibly exacerbated by administration of chemotherapy (2). OM leads to increased hospitalizations, aspiration risk, prolonged recovery, treatment breaks, and increased medical care costs (3-7). Extreme pain and dysphagia often lead to anorexia and dehydration, necessitating the placement of feeding tubes $(8,9)$. Most $\mathrm{OM}$ therapies rely on symptom management with treatments ranging from oral rinses to low-level laser therapy (10). Opioids are often 
necessary for pain management but fail to provide complete relief for many patients (11-13).

Thus, there is a need to investigate supplemental pain management strategies. In HNC patients, OM pain often leads to decreased fluid intake resulting in clinically significant dehydration; this manifests as orthostasis and/or decreased renal function, which necessitates the administration of intravenous (IV) fluids. However, even in the absence of clinically significant dehydration at the midpoint of CRT, recent data from bioelectrical impedance studies demonstrates a positive correlation between increased dehydration and the grade of OM (14). This suggests that IV fluid administration at the midpoint of CRT, even in the absence of clinical dehydration, may alleviate OM pain. The purpose of the current study is to evaluate the role of IV fluids in OM pain management in patients undergoing CRT for HNC.

We present the following article in accordance with the STROBE reporting checklist (available at http://dx.doi. org/10.21037/atm-20-3910).

\section{Methods}

The study was conducted in accordance with the Declaration of Helsinki (as revised in 2013). The study was approved by the Roswell Park Comprehensive Cancer Center Institutional Review Board (EDR-103707) and informed consent was taken from all individual participants. Patients on treatment or who had recently completed radiation for $\mathrm{HNC}$ were evaluated for pain during routine clinical evaluations. All patients were undergoing definitive radiation therapy, the details of chemotherapy and radiation at our institution have been previously described $(15,16)$. Our institutional practice was to prescribe prophylactic gabapentin for all patients to start at the beginning of treatment, with doses starting at $300 \mathrm{mg}$ daily and titrating up to $900 \mathrm{mg}$ three times daily, as tolerated. Subsequent, clinically significant pain was treated per our institutional standard of care, which consisted of acetaminophen/ hydrocodone $7.5 \mathrm{mg} / 325 \mathrm{mg}$ per $15 \mathrm{~mL}$ elixir taken up to four times per day. A fentanyl transdermal patch was prescribed for long acting pain control after short acting opioids were used 3 to 4 times per day, with acetaminophen/ hydrocodone for breakthrough. Fentanyl was started at $25 \mu \mathrm{g} / \mathrm{h}$ and titrated up $100 \mu \mathrm{g} / \mathrm{h}$ as needed.

At any time during radiation treatment and at any point in a patient's analgesic regimen, patients with pain attributed to OM were given IV fluids as per standard clinic protocol. IV fluids typically consisted of 1-2 liters of lactated Ringers (LR). All patients' laboratory record and medical history was reviewed prior to IV fluids. In patients with a history of heart disease, clinical judgment was used to evaluate for any signs or symptoms of volume overload, which would have precluded IV fluids. Patients were routinely monitored by a nurse during fluid administration, and vital signs (including pulse oximetry) were measured after administration and prior to discharge from clinic. Furthermore, adequate time (at least $72 \mathrm{~h}$ ) was allowed between reconsideration of additional IV fluids. Concurrent pain medication (beyond the standard prescribed outpatient pain medication available to the patient) was not provided with fluid administration.

Patients were evaluated with a survey immediately prior to and following IV fluid administration; the survey included a Visual Analog Scale (VAS) to determine pain level. The VAS was chosen as it has been previously validated in the setting of acute pain (17-20). Orthostatic vital signs were measured prior to and following fluid administration. Patient pain medication regimen and medications received during fluid administration were recorded at each interval.

\section{Statistical analysis}

Pain scores were reported as mean and standard deviation (SD). The difference in pre-, post- and follow-up IV fluid administration pain scores was evaluated by two-tailed paired Student's $t$-test using GraphPad Prism (Version 7.04 for Windows, GraphPad Software, La Jolla California USA, www.graphpad.com).

\section{Results}

Table 1 shows baseline patient, tumor and treatment characteristics. Twenty-four patients were available for analysis with 37 fluid administrations. Six instances of fluid administration were excluded for the following: 1 patient refused to complete the survey, 1 patient was subsequently found to have a pulmonary embolism as the source of his pain, 2 patients received concurrent IV Toradol with fluids, and 2 instances in one patient who complained of nausea and exhibited drug seeking behavior. After exclusions, a total of 31 fluid administrations were available for analysis. Twenty-three patients were either receiving or recently completed CRT. One patient received radiation alone. All patients were experiencing head and neck pain at least partially attributed to OM. Twenty-one of 24 (88\%) 
Table 1 Patient age, tumor, and treatment characteristics

\begin{tabular}{|c|c|}
\hline Variables & Value \\
\hline Age $(y)$, median [range] & 63 [48-83] \\
\hline \multicolumn{2}{|c|}{ T stage, $n[\%]$ (AJCC $7^{\text {th }}$ ed.) } \\
\hline Recurrent & $1[4]$ \\
\hline TO & 0 \\
\hline $\mathrm{T} 1$ & 3 [13] \\
\hline $\mathrm{T} 2$ & $11[46]$ \\
\hline T3 & 7 [29] \\
\hline $\mathrm{T} 4$ & $2[8]$ \\
\hline \multicolumn{2}{|c|}{$\mathrm{N}$ stage, $\mathrm{n}[\%]$ (AJCC $7^{\text {th }}$ ed.) } \\
\hline Recurrent & $1[4]$ \\
\hline NO & 3 [13] \\
\hline $\mathrm{N} 1$ & $3[13]$ \\
\hline $\mathrm{N} 2 \mathrm{a}$ & $6[25]$ \\
\hline $\mathrm{N} 2 \mathrm{~b}$ & $6[25]$ \\
\hline $\mathrm{N} 2 \mathrm{c}$ & $2[8]$ \\
\hline N3 & $2[8]$ \\
\hline \multicolumn{2}{|l|}{ Primary tumor site, $\mathrm{n}$ [\%] } \\
\hline Nasopharynx & $1[4]$ \\
\hline Oropharynx & $18[75]$ \\
\hline Oral cavity & $1[4]$ \\
\hline Larynx & $3[13]$ \\
\hline Thyroid & $1[4]$ \\
\hline \multicolumn{2}{|c|}{ Volume of elective radiation, $\mathrm{n}$ [\%] } \\
\hline Unilateral & 7 [29] \\
\hline Bilateral & $15[63]$ \\
\hline None & $2[8]$ \\
\hline
\end{tabular}

patients were prescribed prophylactic gabapentin, as per our institutional standard. Four patients received multiple fluid administrations (range, 2-4). There was a minimum of $72 \mathrm{~h}$ between fluid administrations with a median time of 9 days (range, 3-32 days). No patients received supplemental nutrition via feeding tube at the time of fluid administration.

Of the 23 patients included in the analysis: 8 were found to have orthostatic hypotension prior to fluids, 13 were not orthostatic, and data was unavailable for 2 patients. All patients included in the analysis reported a decrease

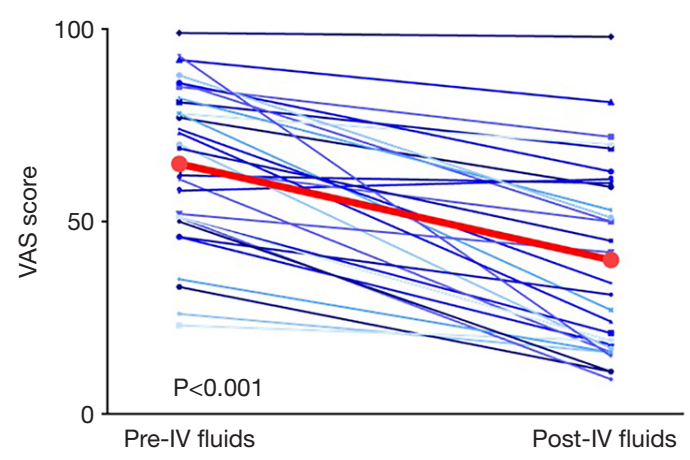

Figure 1 Spaghetti plot of pain scores before and after IV fluids. Each blue line represents a single IV fluid administration. The red line represents change in mean pain value for all $31 \mathrm{IV}$ fluid administrations. IV, intravenous.

in pain. The mean pain score prior to and following IV fluid administration was 6.5 (SD 2.1) and 4.0 (SD 2.4), respectively (Figure 1) $(\mathrm{P}<0.001)$. The follow-up mean pain score (within 8 days) was available for 22 of the 23 patients and was 6.2 (SD 2.2); follow-up mean pain score was not statistically different from baseline $(\mathrm{P}=0.57)$. There was no difference in pain scores based on prophylactic gabapentin use $(\mathrm{P}=0.55)$.

\section{Discussion}

Pain scores using the VAS showed a statistically and clinically significant acute decrease following IV fluid administration. This is the first study to our knowledge documenting the effect of IV fluid administration on OM pain.

Our data is consistent with findings of Brzozowska et al., who showed that HNC patients in the middle of CRT with Grade 3 versus Grade $2 \mathrm{OM}$ had reduction in multiple measures of hydration as measured by bioelectrical impedance (14). Expectedly, consistent with going from Grade 3 to Grade 2 OM, patient-reported pain did not completely resolve in our study; rather, the pain persisted to a milder degree.

Despite the work of Brzozowska et al., the precise mechanism of pain relief following IV fluid administration in $\mathrm{OM}$ is not known. The use of IV fluids has been investigated in other contexts, such as for utility in improving pain, nausea, vomiting, hydration symptoms, and postoperative morbidity, albeit with mixed results (21-26).

IV fluid administration in the pre- and post-operative setting for symptom management has been investigated 
in several clinical trials. In a randomized controlled trial of 120 pediatric patients undergoing strabismus surgery, the combination of dexamethasone and IV LR was found to result in a delay in analgesic requirement, less total acetaminophen use, and significantly lower pain as measured by the VAS (21). Richer et al. randomized pediatric patients to IV fluids with or without the expectation of a pain medication. The authors found that the reduction in pain with IV fluids was relatively small, although a small number of patients did experience some headache relief (27). Spencer et al. evaluated 100 patients undergoing gynecologic surgery and found $1 \mathrm{~L}$ IV sodium lactate solution significantly improved dizziness and nausea (25). Cook et al. conducted a randomized double-blind trial in a similar group of patients and found that IV fluid administration intra-operatively, resulted in a significant reduction in the number of patients who required postoperative medication (including pain medications and antiemetics) and led to more patients ready for discharge at $3 \mathrm{~h}$ (22). This correlates with our observation that there is a statistically and clinically significant improvement in patient pain level without a need for additional pain medication following IV fluid administration. This observation holds true even in patients who do not present with orthostasis.

\section{Limitations}

Though our study had a small sample size, the results are highly significant and unlikely to have been changed. However, there are other limitations to our study. The nature of the IV fluid intervention makes it impossible to give a sham treatment. Consequently, while VAS is wellvalidated for acute pain, we cannot exclude the possibility of a placebo effect impacting the patient's subjective pain assessment. Importantly, at follow up evaluation, pain had increased in most patients, although not back to average initial pain score. This indicates that although there is possibly some lasting pain relief benefit from IV fluid administration, continuation of standard pain medications remained necessary.

\section{Conclusions}

Patients at the mid-point of CRT for HNC benefit from the administration of IV fluids with significant and acute alleviation of acute pain from OM. This holds true even in the absence of orthostasis. The routine use of IV fluids at this time point should be considered as an additional component of the pain management strategy in this population. The pain relief derived from this effect may last several days. IV fluid administration can delay but cannot replace standard pain medications. Multiple administrations of IV fluids should not be prescribed without the proper clinical and laboratory evaluation or in place of appropriate pain medications.

\section{Acknowledgments}

The authors thank Kelsey Smith PA for her tireless efforts to provide excellent care for these patients.

Funding: This work was supported by the National Cancer Institute Cancer Center Support Grant (P30CA016056). Funding source had no role in study design, data collection, data analysis, data interpretation, or writing of the report.

\section{Footnote}

Provenance and Peer Review: This article was commissioned by the Guest Editor (Dr. Mukund Seshadri) for the series "Head and Neck Cancers - Disease Biology, Diagnostics, Prevention and Management" published in Annals of Translational Medicine. The article has undergone external peer review.

Reporting Checklist: The authors have completed the STROBE reporting checklist. Available at http://dx.doi. org/10.21037/atm-20-3910

Data Sharing Statement: Available at http://dx.doi. org/10.21037/atm-20-3910

Conflicts of Interest: All authors have completed the ICMJE uniform disclosure form (available at http://dx.doi. org/10.21037/atm-20-3910). The series "Head and Neck Cancers - Disease Biology, Diagnostics, Prevention and Management" was commissioned by the editorial office without any funding or sponsorship. The authors have no other conflicts of interest to declare.

Ethical Statement: The authors are accountable for all aspects of the work in ensuring that questions related to the accuracy or integrity of any part of the work are appropriately investigated and resolved. The study was conducted in accordance with the Declaration of Helsinki (as revised in 2013). The study was approved by the Roswell Park Comprehensive Cancer Center Institutional Review 
Board (EDR-103707) and informed consent was taken from all individual participants.

Open Access Statement: This is an Open Access article distributed in accordance with the Creative Commons Attribution-NonCommercial-NoDerivs 4.0 International License (CC BY-NC-ND 4.0), which permits the noncommercial replication and distribution of the article with the strict proviso that no changes or edits are made and the original work is properly cited (including links to both the formal publication through the relevant DOI and the license). See: https://creativecommons.org/licenses/by-nc-nd/4.0/.

\section{References}

1. Mirabile A, Airoldi M, Ripamonti C, et al. Pain management in head and neck cancer patients undergoing chemo-radiotherapy: Clinical practical recommendations. Crit Rev Oncol Hematol 2016;99:100-6.

2. O'Connor P, Bisson J, Asplin P, et al. Retrospective analysis of self-reporting pain scores and pain management during head and neck IMRT radiotherapy: A single institution experience. Radiography (Lond) 2017;23:103-6.

3. Trotti A. Toxicity in head and neck cancer: a review of trends and issues. Int J Radiat Oncol Biol Phys 2000;47:1-12.

4. Trotti A, Bellm LA, Epstein JB, et al. Mucositis incidence, severity and associated outcomes in patients with head and neck cancer receiving radiotherapy with or without chemotherapy: a systematic literature review. Radiother Oncol 2003;66:253-62.

5. Rose-Ped AM, Bellm LA, Epstein JB, et al. Complications of radiation therapy for head and neck cancers. The patient's perspective. Cancer Nurs 2002;25:461-7; quiz 468-9.

6. Nonzee NJ, Dandade NA, Patel U, et al. Evaluating the supportive care costs of severe radiochemotherapyinduced mucositis and pharyngitis: results from a Northwestern University Costs of Cancer Program pilot study with head and neck and nonsmall cell lung cancer patients who received care at a county hospital, a Veterans Administration hospital, or a comprehensive cancer care center. Cancer 2008;113:1446-52.

7. Han HR, Hermann GM, Ma SJ, et al. Matched pair analysis to evaluate hospitalization during radiation therapy for head and neck cancer as an early marker of survival. Oral Oncol 2020;109:104854.

8. Kramer S, Newcomb M, Hessler J, et al. Prophylactic versus reactive PEG tube placement in head and neck cancer. Otolaryngol Head Neck Surg 2014;150:407-12.
9. Strom T, Trotti AM, Kish J, et al. Risk factors for percutaneous endoscopic gastrostomy tube placement during chemoradiotherapy for oropharyngeal cancer. JAMA Otolaryngol Head Neck Surg 2013;139:1242-6.

10. Maria OM, Eliopoulos N, Muanza T. Radiation-Induced Oral Mucositis. Front Oncol 2017;7:89.

11. Alfieri S, Ripamonti CI, Marceglia S, et al. Temporal course and predictive factors of analgesic opioid requirement for chemoradiation-induced oral mucositis in oropharyngeal cancer. Head Neck 2016;38 Suppl 1:E1521-7.

12. Elting LS, Keefe DM, Sonis ST, et al. Patient-reported measurements of oral mucositis in head and neck cancer patients treated with radiotherapy with or without chemotherapy: demonstration of increased frequency, severity, resistance to palliation, and impact on quality of life. Cancer 2008;113:2704-13.

13. Hermann GM, Iovoli AJ, Platek AJ, et al. A singleinstitution, randomized, pilot study evaluating the efficacy of gabapentin and methadone for patients undergoing chemoradiation for head and neck squamous cell cancer. Cancer 2020;126:1480-91.

14. Brzozowska A, Mlak R, Golebiowski P, et al. Status of hydration assessed by bioelectrical impedance analysis: a valuable predictive factor for radiation-induced oral mucositis in head and neck cancer patients. Clin Transl Oncol 2019;21:615-20.

15. McCloskey SA, Jaggernauth W, Rigual NR, et al. Radiation treatment interruptions greater than one week and low hemoglobin levels $(12 \mathrm{~g} / \mathrm{dL})$ are predictors of local regional failure after definitive concurrent chemotherapy and intensity-modulated radiation therapy for squamous cell carcinoma of the head and neck. Am J Clin Oncol 2009;32:587-91.

16. Platek ME, McCloskey SA, Cruz M, et al. Quantification of the effect of treatment duration on local-regional failure after definitive concurrent chemotherapy and intensitymodulated radiation therapy for squamous cell carcinoma of the head and neck. Head Neck 2013;35:684-8.

17. Ferreira-Valente MA, Pais-Ribeiro JL, Jensen MP. Validity of four pain intensity rating scales. Pain 2011;152:2399-404.

18. Bahreini M, Jalili M, Moradi-Lakeh M. A comparison of three self-report pain scales in adults with acute pain. J Emerg Med 2015;48:10-8.

19. Rodriguez CS, McMillan S, Yarandi H. Pain measurement in older adults with head and neck cancer and communication impairments. Cancer Nurs 2004;27:425-33.

20. Hawker GA, Mian S, Kendzerska T, et al. Measures of adult pain: Visual Analog Scale for Pain (VAS Pain), 
Numeric Rating Scale for Pain (NRS Pain), McGill

Pain Questionnaire (MPQ), Short-Form McGill Pain Questionnaire (SF-MPQ), Chronic Pain Grade Scale (CPGS), Short Form-36 Bodily Pain Scale (SF-36 BPS), and Measure of Intermittent and Constant Osteoarthritis Pain (ICOAP). Arthritis Care Res (Hoboken) 2011;63 Suppl 11:S240-52.

21. Sayed JA, F Riad MA, M Ali MO. Comparison of dexamethasone or intravenous fluids or combination of both on postoperative nausea, vomiting and pain in pediatric strabismus surgery. J Clin Anesth 2016;34:136-42.

22. Cook R, Anderson S, Riseborough M, et al. Intravenous fluid load and recovery. A double-blind comparison in gynaecological patients who had day-case laparoscopy. Anaesthesia 1990;45:826-30.

23. Bruera E, Hui D, Dalal S, et al. Parenteral hydration in

Cite this article as: Rivers CI, Iovoli AJ, Chatterjee U, Hermann GM, Singh AK. Intravenous fluids for pain management in head and neck cancer patients undergoing chemoradiation. Ann Transl Med 2021;9(10):912. doi: 10.21037/ atm-20-3910 patients with advanced cancer: a multicenter, doubleblind, placebo-controlled randomized trial. J Clin Oncol 2013;31:111-8.

24. Bruera E, Sala R, Rico MA, et al. Effects of parenteral hydration in terminally ill cancer patients: a preliminary study. J Clin Oncol 2005;23:2366-71.

25. Spencer EM. Intravenous fluids in minor gynaecological surgery. Their effect on postoperative morbidity. Anaesthesia 1988;43:1050-1.

26. Balbin JE, Nerenberg R, Baratloo A, et al. Intravenous fluids for migraine: a post hoc analysis of clinical trial data. Am J Emerg Med 2016;34:713-6.

27. Richer L, Craig W, Rowe B. Randomized controlled trial of treatment expectation and intravenous fluid in pediatric migraine. Headache 2014;54:1496-505. 